Proc. XIX International School of Semiconducting Compounds, Jaszowiec 1990

\title{
SEMI-INSULATING TRANSITION METAL-DOPED III-V MATERIALS
}

\author{
ANDRZEJ M. HENNEL \\ Institute of Experimental Physics, Warsaw University, Hoża 69, 00-681 Warsaw, Poland \\ (Received August 8, 1990)
}

\begin{abstract}
This review surveys the properties of transition metal (TM) doped semiinsulating (SI) III-V semiconductors. After a general definition of a SI material, a simple model of a SI crystal with a midgap donor and shallow impurities is discussed. A short history, main properties, and thermal stability problems of SI Cr-doped $\mathrm{GaAs}$ are presented. The puzzling problem of SI V-doped GaAs is explained. Several dopants ( $\mathrm{Cr}, \mathrm{Fe}, \mathrm{Co}$, and $\mathrm{Ti}$ ) in SI InP are discussed in terms of the resistivities obtained, as well as thermal stability. Finally, GaP and GaInAs high resistivity systems are considered.
\end{abstract}

PACS numbers: 71.55.Eq, 72.80.Ey, 81.60.Cp

\section{Introduction}

Transition metal (TM) impurities in III-V compounds have been investigated for a quarter of a century. These omnipresent, multicharge, and multilevel deep centers, acting as donors, acceptors and sometimes double acceptors, have very significant impact on optical, transport, magnetic, and other properties of III-V semiconductors. Several review articles have recently been devoted to this subject (see, for example, [1-4]).

The first, and still the most important, application of transition metals impurities in III-V compounds is their ability to compensate shallow impurities and thus produce semi-insulating (SI) materials.

The term semi-insulating material has been used for many years, being introduced into the Physics Abstracts in 1969. However, in the late seventies, their importance has grown seriously, and since 1980 , a series of conferences devoted exclusively to SI III-V materials has been organized [5-9]. The sixth of these will take place three weeks from now, in Toronto. 


\section{General definition}

A semi-insulated material may be defined as a high resistivity semiconductor crystal with the Fermi level firmly located in a midgap position. However, it cannot be an intrinsic semiconductor, because the Fermi level position should not change after standard thermal annealings which may generate shallow crystal defects. Furthermore, for many intentionally undoped crystals, concentrations of electrically active impurities cannot be made much smaller than $10^{15} \mathrm{~cm}^{-3}$.

A semi-insulated material cannot also be a crystal which possesses only one dominant deep defect. In such a case, the Fermi level lies between this level and one of the band edges. Therefore, to fulfill our definition, a semi-insulating material must possess a deep defect partly compensated by shallow impurities.

Let us consider a model SI semiconductor with $N_{D}$ midgap donors, $N_{A S}$ shallow acceptors, and $N_{D S}$ shallow donors. To calculate the free electron and free hole concentration (according to [10] and [11]) we take the following parameters, corresponding to $\mathrm{GaAs}$ at the room temperature [12]: the effective state density $N_{c}=\left[2\left(2 \pi m_{e}^{*} k\right)^{3 / 2} / h^{3}\right] T^{\mathrm{j}} 3 / 2=4.21 \times 10^{17} \mathrm{~cm}^{-3}$; the intrinsic carrier pair density $n_{i}=2.25 \times 10^{6} \mathrm{~cm}^{-3}$; the energy gap $E_{g}=1.42 \mathrm{eV}$; the deep donor midgap position $E_{D}=E_{g} / 2=0.71 \mathrm{eV}$, their concentration $N_{D}=10^{14} \div 10^{17} \mathrm{~cm}^{-3}$; and identical degeneracies of the occupied and unoccupied donor states $\left(g_{D^{0}}=g_{D^{+}}\right)$.

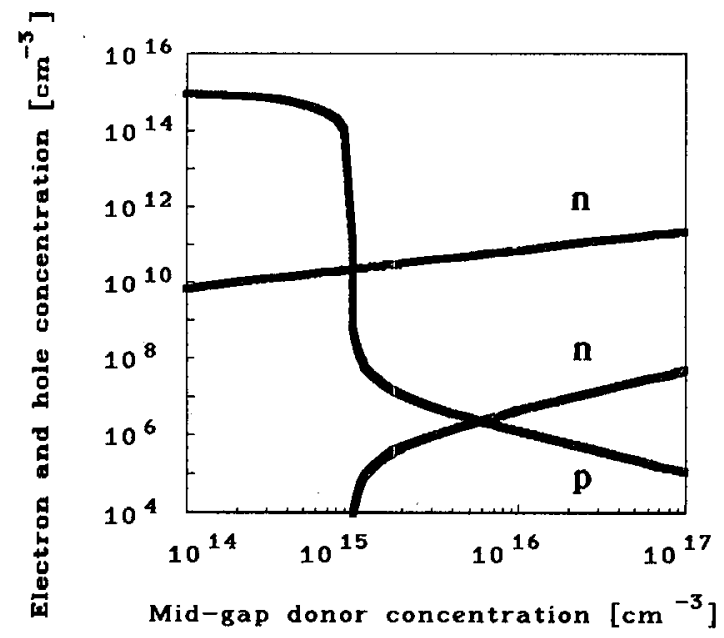

Fig.1. Free carrier concentration in a model SI crystal as a function of the midgap donor concentration. The two crossing curves correspond to $N_{A S}-N_{D S}=10^{15} \mathrm{~cm}^{-3}$, the straight line corresponds to $N_{A S}-N_{D S}=0$.

Figure 1 presents results of our calculations of $n\left(N_{D}\right)$ and $p\left(N_{D}\right)$ for $N_{A S}-N_{D S}$ equal to zero and $10^{15} \mathrm{~cm}^{-3}$, respectively. One can see that for $N_{A S}-N_{D S}=0, n=10^{10} \div 10^{11} \mathrm{~cm}^{-3}$, which corresponds to $\rho$ of only $10^{3} \div$ $10^{4} \Omega \mathrm{cm}$. However, in the latter case, the free electron and free hole concentrations 
obtained for the midgap donor concentration, remain within an order of magnitude of the intrinsic carrier concentration, even though $N_{D}$ varies from $1.5 \times 10^{15}$ to around $5 \times 10^{16} \mathrm{~cm}^{-3}$. Such a material is sometimes called a semi-intrinsic crystal.

Figure 2 presents results of calculations of the resistivity of our model semiconductor as a function of $N_{D}$, when the difference $N_{A S}-N_{D S}$ is again equal to $10^{15} \mathrm{~cm}^{-3}$, and the concentration of ionized centers is of the order of $10^{16} \mathrm{~cm}^{-3}$.

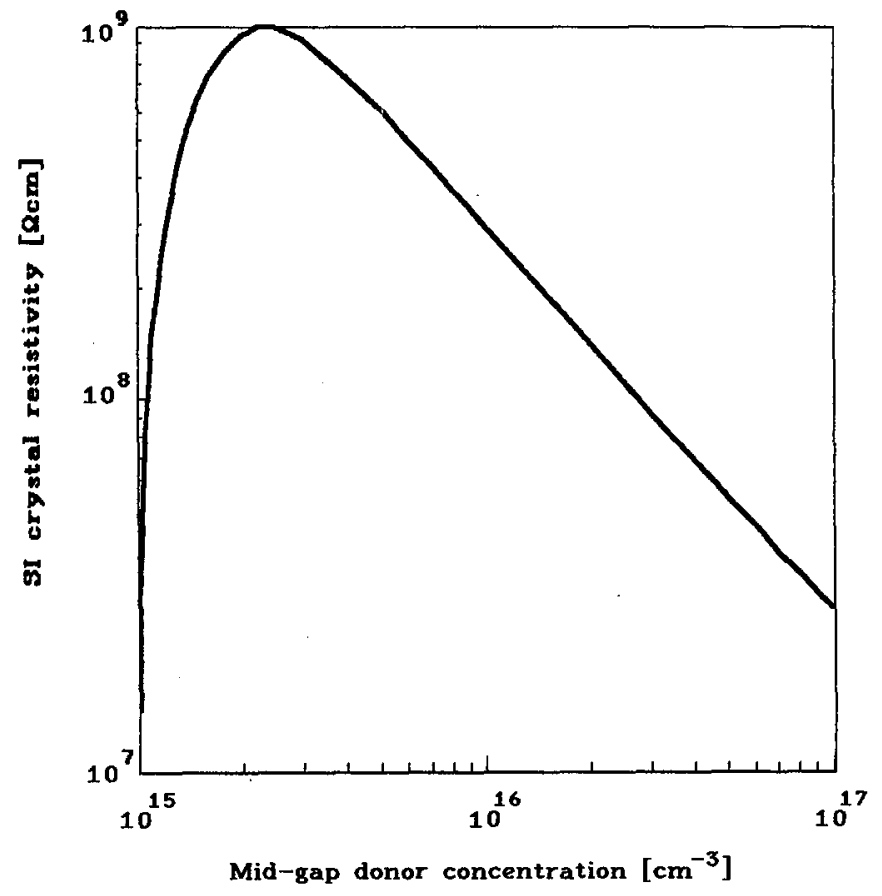

Fig.2. The resistivity of a model SI crystal as a function of the midgap donor concentration for $N_{A S}-N_{D S}=10^{15} \mathrm{~cm}^{-3}$.

Free carrier room temperature mobilities were thus estimated as $\mu_{e}=5000 \mathrm{~cm}^{2} / \mathrm{Vs}$ for electrons and $\mu_{h}=390 \mathrm{~cm}^{2} / V s$ for holes [13]. The resistivity values obtained remain above $10^{7} \Omega \mathrm{cm}$ for more than two orders of magnitude change of $N_{D}$. The $\rho\left(N_{D}\right)$ curve reaches a maximum at resistivity

$$
\rho_{\max }=\left[2 e n_{i}\left(\mu_{e} \mu_{h}\right)^{\frac{1}{2}}\right]^{-1}=10^{9} \Omega \mathrm{cm}
$$

which corresponds to the ratio $p / n=\mu_{e} / \mu_{h}=13$, i.e. $p=8.1 \times 10^{7} \mathrm{~cm}^{-3}$ and $n=6.3 \times 10^{5} \mathrm{~cm}^{-3}$. 


\section{TM-doped SI GaAs crystals}

To obtain an ideal semi-insulating TM-doped semiconductor, one should choose a TM impurity with the following properties: a) a mid-gap acceptor or mid-gap donor level, b) good thermal stability. It is not easy to fulfill both these conditions. The first TM-doped SI material was Cr-doped GaAs. Chromium acts as a deep, mid-gap acceptor in GaAs (Fig. 3), as was shown by Haisty and Cronin

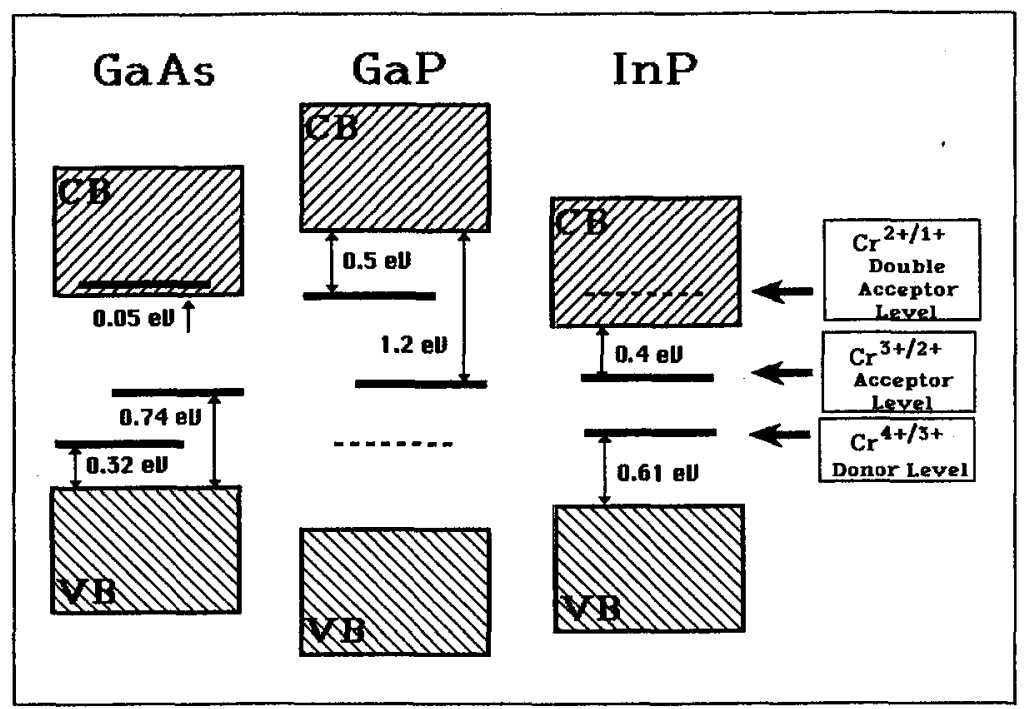

Fig.3. The energy levels of the chromium impurity in GaAs, GaP, and InP. The dashed lines represent the levels which are predicted but not yet observed.

from Texas Instruments in 1964 [14] (see Fig. 4). Thus, chromium impurities are able to compensate the shallow donors ( $\mathrm{Si}, \mathrm{S}, \mathrm{Se}$ and $\mathrm{Te}$ ) typically present in the concentration range of $10^{15}-10^{17} \mathrm{~cm}^{-3}$ in horizontal Bridgman (HB) and liquid encapsulated Czochralski (LEC) GaAs crystals grown in silica crucibles. For concentration of chromium impurities $N_{\mathrm{CR}}>N_{D S}-N_{A S}$, the Fermi level is firmly located in the mid-gap position. This property of chromium was the basis of U.S. Patent \#3344071 (1967), due to G.R.Cronin. The patent concerns growth of SI GaAs crystals with resistivity values above $10^{8} \Omega \mathrm{cm}$ by doping with $0.2-0.5 \mathrm{ppm}$ of chromium. One of the examples presented in this patent is a $100 \mathrm{~g} \mathrm{GaAs}$ crystal, grown in an aluminum crucible, doped with $100 \mathrm{mg}$ of chromium. The crystal had resistivity equal to $3.5 \times 10^{8} \Omega \mathrm{cm}$.

A detailed analysis of the LEC Cr-doped GaAs resistivity performed about two decades later on 1-4 kg crystals is shown in Fig. 5 [15]. The Cr concentration was measured with the help of a radiotracer ${ }^{51} \mathrm{Cr}$ technique. Two regions of almost constant resistivity are evident, with an apparent threshold at the Cr concentration of about $1 \mathrm{ppm}$. The lower resistivity regime $\left(1 \div 2 \times 10^{8} \Omega \mathrm{cm}\right)$ corresponds to 


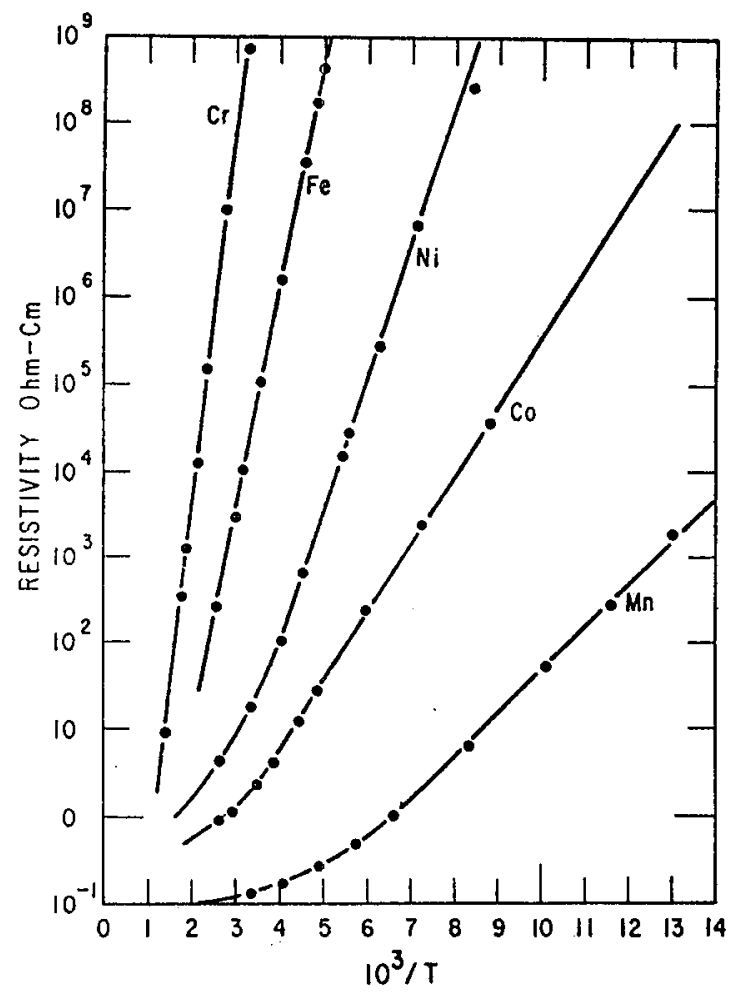

Fig.4. Variation of resistivity as a function of temperature for TM-doped GaAs [14].

nominally undoped SI GaAs with the Fermi level located probably at the deep donor EL2 (see, for example, [16]). In the higher resistivity regime $\left(5 \div 9 \times 10^{8} \Omega \mathrm{cm}\right)$, the Fermi level is really pinned to the chromium $\mathrm{Cr}^{3+/ 2+}$ acceptor level.

The only serious technological problem with Cr-doped GaAs crystals was the poor thermal stability of chromium. In GaAs wafers annealed at temperatures in excess of about $700^{\circ} \mathrm{C}$, changes in conductivity type are likely to occur [17]. These effects are not always reproducible. The most frequent effect was conversion to $p$-type conductivity, but conversion to $n$-type was sometimes also observed. All these effects were surface phenomena taking place in a few micron thick layers. Furthermore, during epitaxial crystal growth on SI Cr-doped wafers, the chromium atoms diffuse out of the substrates, and the first few microns of a nominally undoped epitaxial layer have a resistivity that is much higher than expected. Moreover, accumulation of chromium was observed at surfaces after post-implantation annealing, or at substrate-layer interfaces after epitaxial growth (see [17] and [18]). This outdiffusion process was found even at relatively low temperatures $\left(500-700^{\circ} \mathrm{C}\right.$ ) (see Fig. 6), and may have serious impact on electronic device properties.

In the early eighties, the above mentioned thermal stability problems, as well 


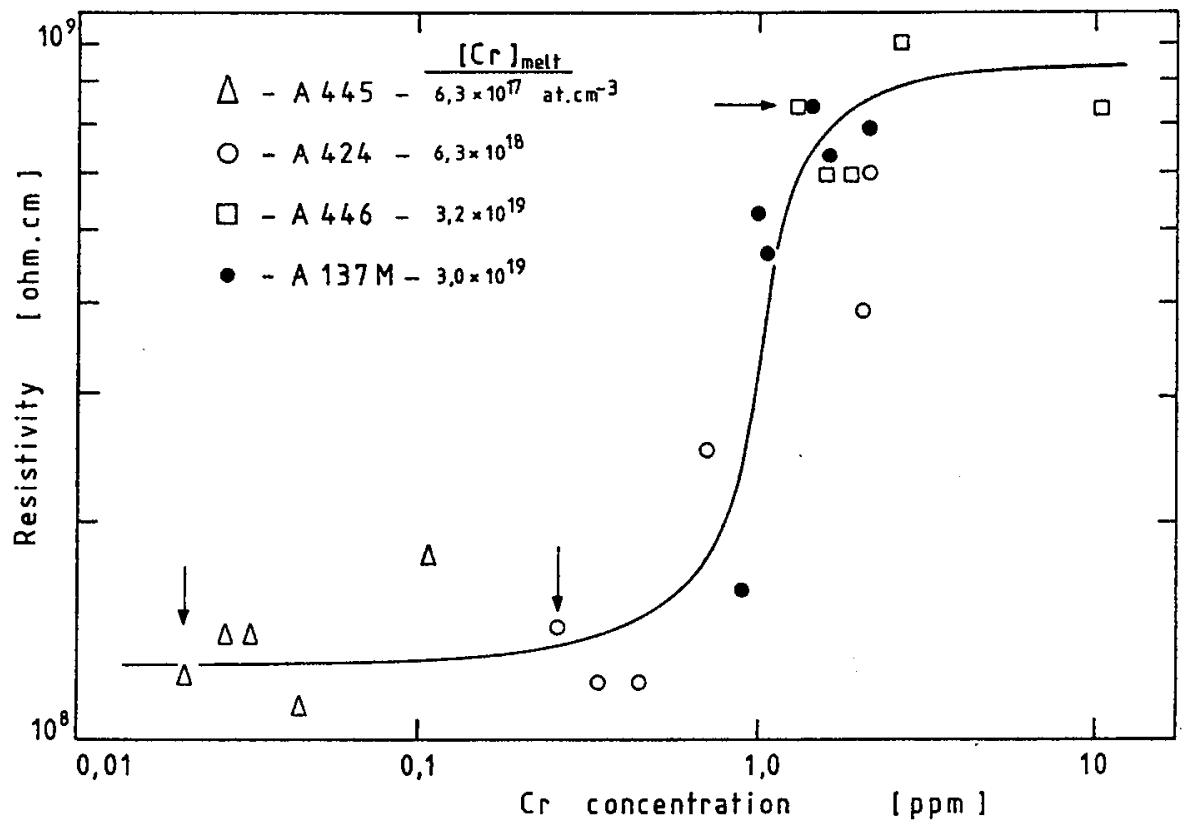

Fig.5. SI GaAs resistivity as a function of $\mathrm{Cr}$ concentration, using samples taken from four separate crystals [15].

as successful growth of undoped SI GaAs LEC material grown in PBN crucibles, reduced the role of SI Cr-doped GaAs. However, about $50 \%$ of production of Sumitomo Electric Industries (the first GaAs world producer) is still 3-inch HB Cr-doped GaAs grown in 1 meter long quartz crucibles.

During the last few years, serious improvements in HB growth technology have made growth of thermally stable Cr-doped GaAs possible. The general idea is to reduce the dislocation density and, as a result, to eliminate the mechanism of chromium diffusion through extended crystal defects. One of the methods of dislocation density reduction is strong $\left(5 \div 50 \times 10^{19} \mathrm{~cm}^{-3}\right)$ doping with indium (patented in 1970 [20]). Indium (and also other isoelectronic impurities) does not affect the electrical properties of SI GaAs, but is hardening the GaAs matrix and, as a result, strongly reduces its dislocation density. In 1985, a co-doping of GaAs with $\mathrm{Cr}$ and In was proposed in two patents [21-22], as a method of obtaining thermally stable SI material. Recently, thermally stable HB Cr-doped SI GaAs crystals were reported by Sumitomo Electric Industries [23-24]. These low dislocation density $\left(1 \div 5 \times 10^{3} \mathrm{~cm}^{-2}\right)$, 2- and 3-inch, Cr-doped SI GaAs crystals were grown in a state-of-the-art three zone (3T-HB) Bridgman furnace. A second group of crystals was additionally co-doped with indium at a relatively low concentration level $\left(1.5 \div 4 \times 10^{19} \mathrm{~cm}^{-3}\right)$. The latter crystals have drastically lower dislocation densities $\left(<10^{3} \mathrm{~cm}^{-2}\right)$ and much smaller radial variation of resistivity than those 

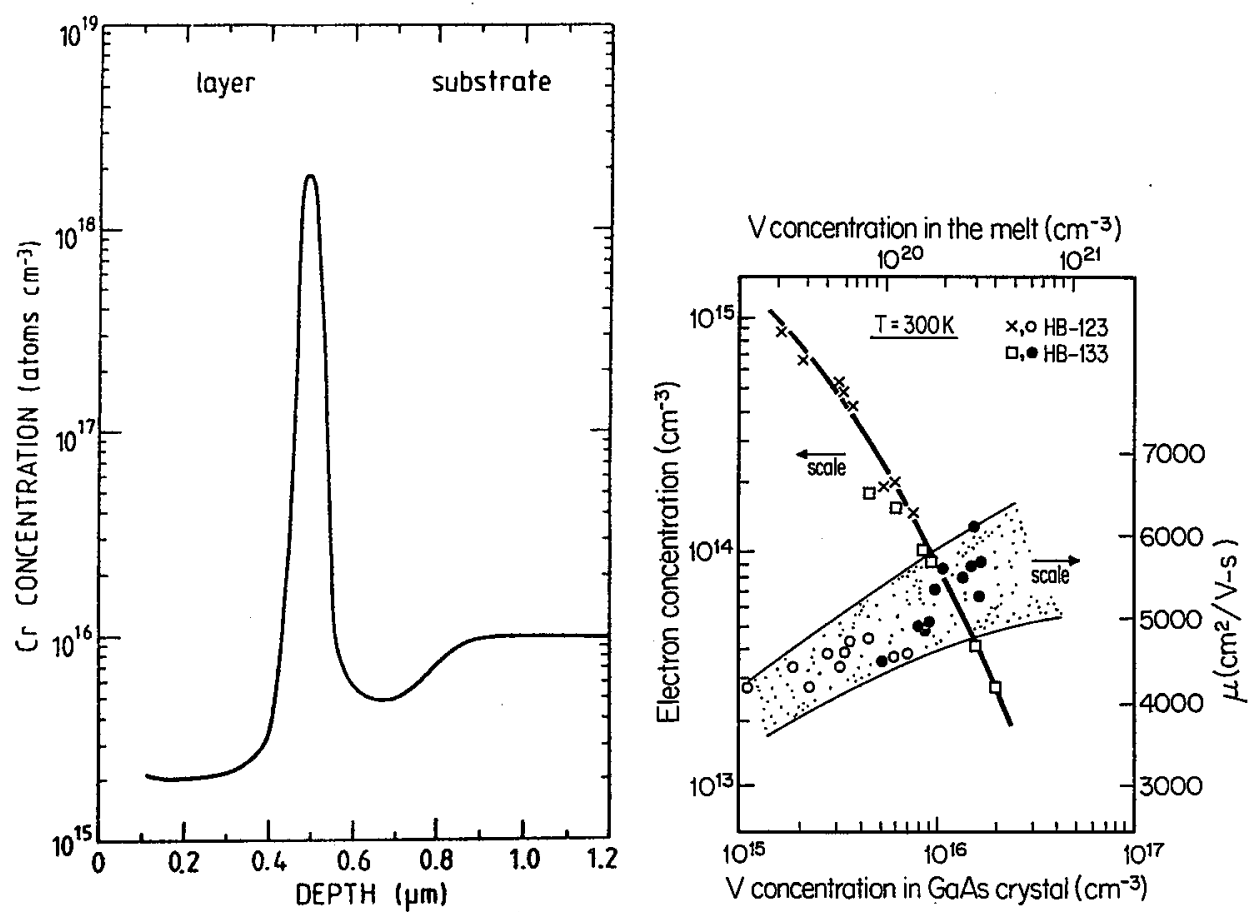

Fig.6. Chromium profile in an MBE layer, measured by SIMS [19]. The substrate was heated to $530^{\circ} \mathrm{C}$ for 30 minutes before growth.

Fig.7. Free electron concentration and their mobility as a function of vanadium concentration for several samples from two $\mathrm{HB}$ GaAs crystals [30].

of the first group. Crystals from both the groups remained stable after 30 minute annealing at $850^{\circ} \mathrm{C}$ in $\mathrm{AsH}_{3}$ atmosphere. Thus, the SI HB GaAs:Cr,In material is already considered as one of the four major SI GaAs substrates for the nineties.

Some years ago, several V-doped SI GaAs crystals and layers with resistivities of around $10^{7}-10^{8} \Omega \mathrm{cm}$ were also reported - LEC [25], VPE [26], MOCVD [27], and HB [28]. This material could be a very promising one, since the diffusivity of $\mathrm{V}$ in GaAs was shown to be one order of the magnitude lower than that of $\mathrm{Cr}$ [25]. However, detailed optical and electrical investigations of a series of $\mathrm{V}$-doped crystals have clearly shown [28-29] that the vanadium $\mathrm{V}^{3+/ 2+}$ acceptor level is located $0.15 \mathrm{eV}$ below the bottom of the conduction band and the mid-gap level responsible for the high resistivity of these materials is the EL2 deep donor. The role of vanadium in the crystal growth process may be explained with the help of Fig. 7 [30]. Acting purely as an acceptor, vanadium should compensate shallow donors and decrease the free electron mobility. The observed mobility enhancement as a function of $V$ concentration, strongly suggests that a purification process is taking place. SIMS measurements have confirmed this hypothesis. Silicon and sulphur 
concentrations, which normally increase from the seed to the tail end of a $\mathrm{HB}$ crystal, strongly decrease in the presence of vanadium. Thus, vanadium plays a mainly chemical role (gettering of donors) during the crystal growth process [30]. Recent MOVPE growth of V-doped GaAs [31] has confirmed this interpretation. It was shown that only less than $1 \%$ of vanadium atoms in GaAs MOVPE layers are electrically active. Furthermore, attempts to create a V-related complex (suggested by many authors) by implantation into $\mathrm{GaAs}$ of $\mathrm{V}, \mathrm{O}, \mathrm{V}+\mathrm{O}, \mathrm{Si}+\mathrm{V}+\mathrm{O}$, and $\mathrm{S}+\mathrm{V}+\mathrm{O}$, for variety of doses and at different energies, have led to an unequivocally negative result [31].

\section{TM-doped SI InP crystals}

The first SI InP reported was a Cr-doped material analogous to GaAs [32]. However, the chromium $\mathrm{Cr}^{3+/ 2+}$ acceptor level is located in the upper part of the energy gap in InP (see Fig. 3) and only $10^{3}-10^{5} \Omega \mathrm{cm}$ resistivity range could be achieved at the room temperature. In 1975, SI Fe-doped InP crystals were obtained at Nippon Electric [33]. The mid- gap position of the $\mathrm{Fe}^{3+/ 2+}$ acceptor level (see Fig. 8) makes it possible to obtain SI InP with resistivities of around $10^{7}-10^{8} \Omega \mathrm{cm}$.

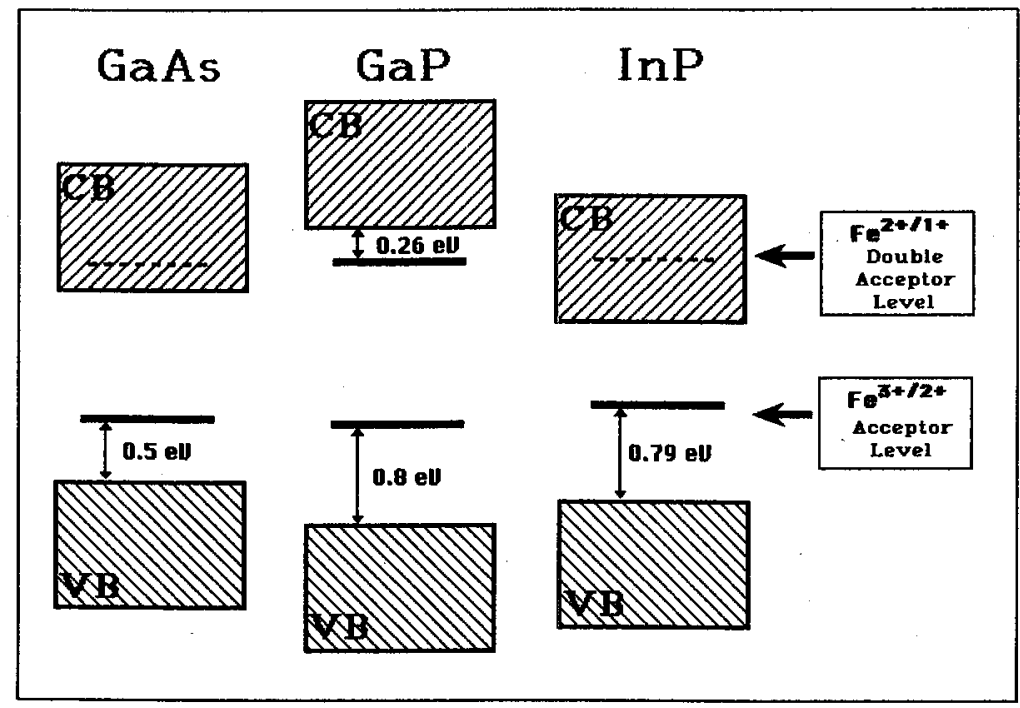

Fig.8. The energy levels of the iron impurity in GaAs, GaP, and InP. The dashed lines represent levels which are predicted but not yet observed.

Up to now, this material remains the main SI InP substrate. State-of-the-art 2-inch crystals with dislocation densities of around $1 \div 4 \times 10^{3} \mathrm{~cm}^{-2}$ are grown by the Electro-Dynamic Gradient (EDG) (also called "Electronic Bridgman") technique at the AT\&T Bell Laboratories [34] or by the multi-zone LEC technique at 
Sumitomo Electric [35]. Unfortunately, outdiffusion properties similar to those of $\mathrm{Cr}$ in GaAs were reported for Fe in InP [17], [36] (see Fig. 9).

A UNANNEALED InP ( $\left.F_{\theta}\right)$

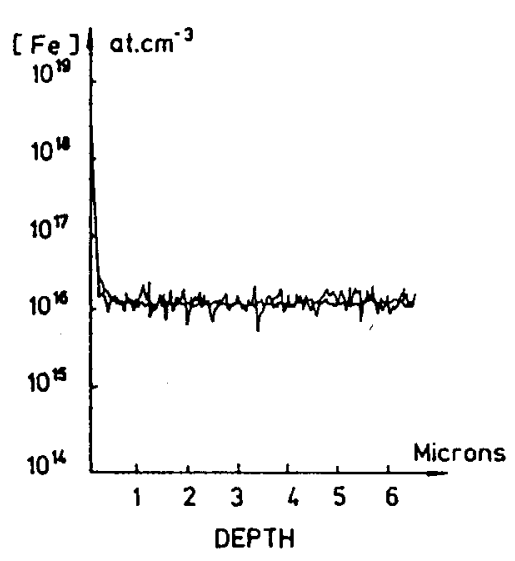

B ANNEALED InP (Fe) $\left(1000^{\circ} \mathrm{C}-3^{\mathrm{h}} 30\right)$

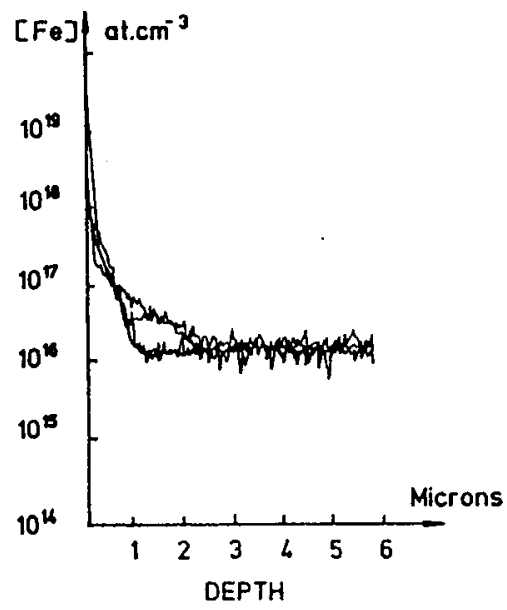

C UNANNEALED InP (Fe.Ga)

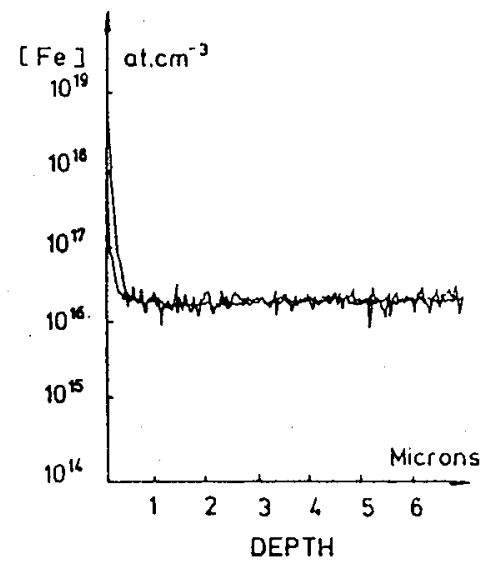

D ANNEALED InP (Fe.Ga) $\left(1000^{\circ} \mathrm{C}-3^{\mathrm{n}} 30\right)$

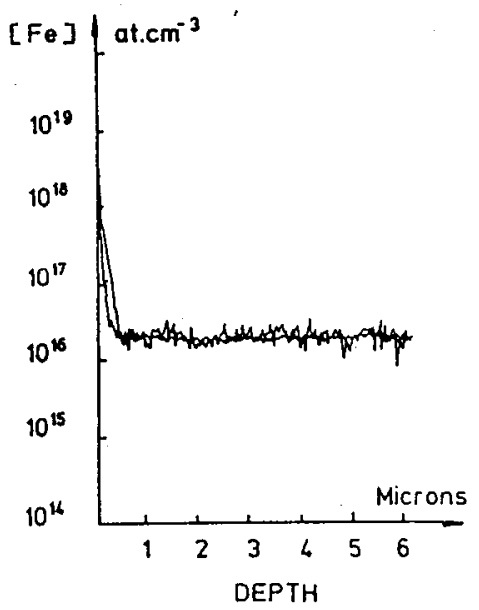

Fig.9. A comparison of the Fe distribution in InP:Fe and InP:Fe + Ga wafers before and after annealing under phosphorus vapor pressure [37].

Other TM acceptors, such as Co, were also used to obtain SI InP (see, for example, [38]), but due to the $\mathrm{Co}^{3+/ 2+}$ level being in the lower part of the energy gap (at about $E_{v}+0.3 \mathrm{eV}[4]$ ), the resistivity obtained is only around $10^{5} \Omega \mathrm{cm}$. Furthermore, the Co impurity diffusion coefficient is larger than that for $\mathrm{Fe}$ and 
one cannot expect thermal stability better than that for Fe-doped InP for this material.

In the mid-eighties, this situation stimulated serious activity in search of new, thermally stable SI InP TM-doped substrates [39].

Fe-doped InP material can also be improved by co-doping with the isoelectronic $\mathrm{Ga}$ impurity [37], or $\mathrm{Ga}$ and As impurities [40], which reduces the dislocation density. Thermal stability of $\mathrm{Fe}$ and Ga-doped InP was shown to be much better than that resulting with no Ga co-doping [37] (see Fig. 9).

Another possibility, developed recently for InP, is co-doping with deep TM donors and shallow acceptors. Such an idea was proposed for two deep mid-gap TM donors in InP ( $\mathrm{Ti}$ and $\mathrm{Cr}$ ) [41-42] (see Fig. 3 and 10). ST crystals of $\mathrm{Cr}$-doped

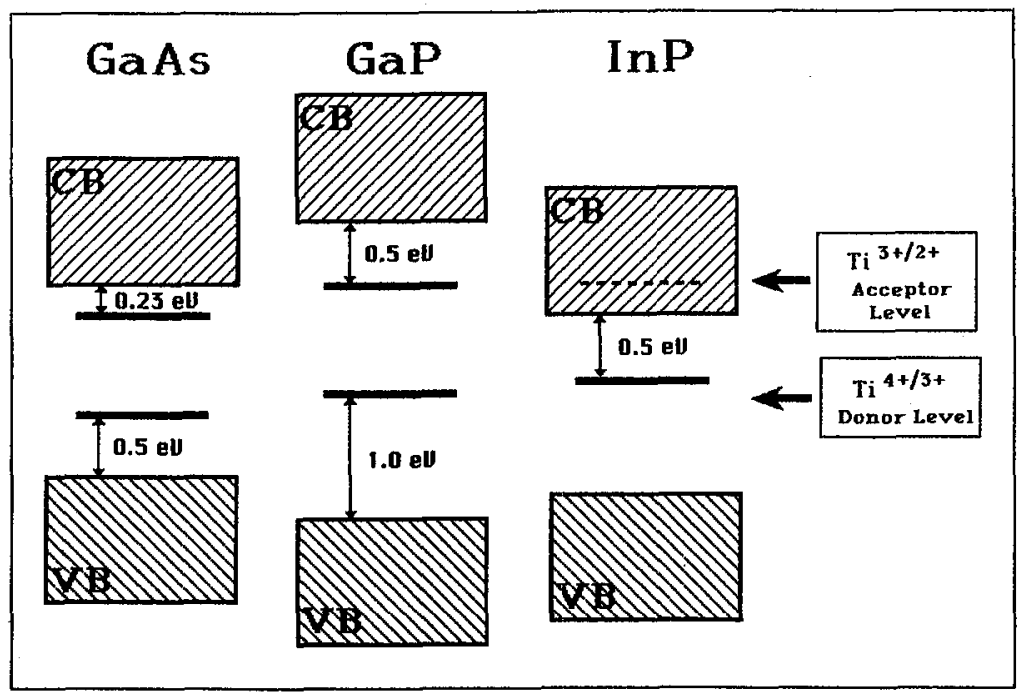

Fig.10. The energy levels of the titanium impurity in GaAs, GaP, and InP. The dashed line represents a level which is predicted but not yet observed.

InP, co-doped with $\mathrm{Cd}$ or $\mathrm{Hg}$, reached resistivities of up to $10^{6} \Omega \mathrm{cm}$ [43]. However, the thermal stability of $\mathrm{Cr}$ was found to be similar to that of $\mathrm{Fe}$ in InP.

The titanium $\mathrm{Ti}^{4+/ 3+}$ donor level has been much more promising, because diffusivity trends of TM in III-V crystals predict [44] that it will have a much lower diffusivity than is the case for iron. There are several values of the titanium donor ionization energy reported in the literature, the most reasonable one being $E_{c}=0.5 \mathrm{eV}$, obtained with the help of high pressure measurements [45]. SI crystals of Ti-doped $\mathrm{InP}$, co-doped with $\mathrm{Be}, \mathrm{Cd}, \mathrm{Hg}$, and $\mathrm{Zn}$, with resistivities of up to $5 \times 10^{6} \Omega \mathrm{cm}$, were grown by several groups (see Table I). To check their thermal stability, Ti profiles were measured in $\mathrm{Ti}+\mathrm{Hg}$-doped $\mathrm{InP}$ [37], as well as $\mathrm{Ti}$ and $\mathrm{Zn}$ profiles in Ti + Zn-doped InP [48] (see Fig. 11). All these measurements, performed in the $800-975^{\circ} \mathrm{C}$ temperature range, showed the very high thermal stability of 


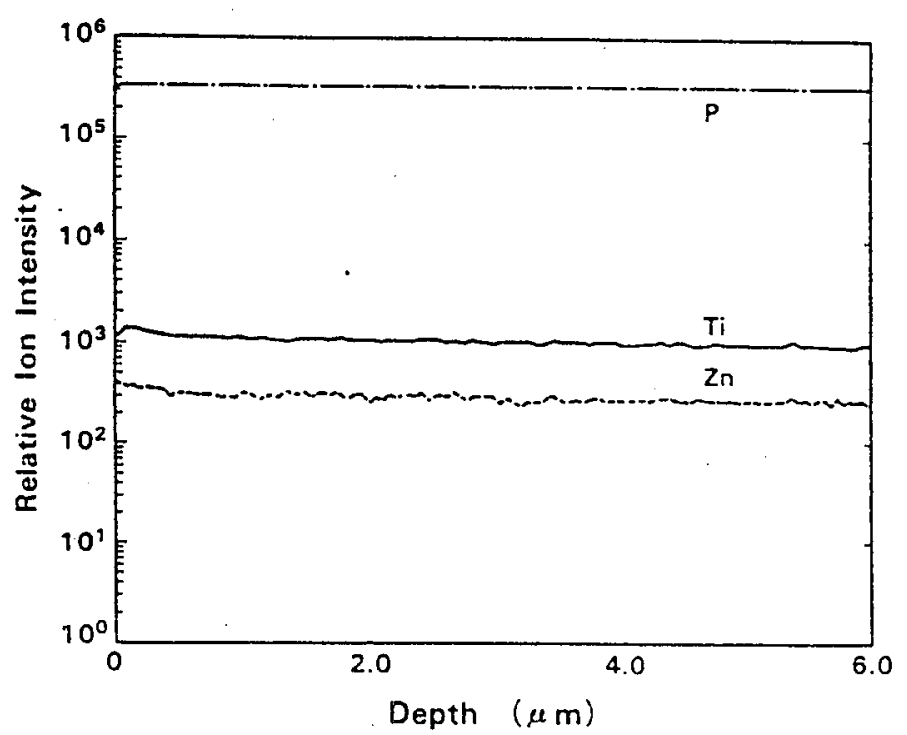

Fig.11. SIMS profiles of $\mathrm{Ti}$ and $\mathrm{Zn}$ dopants in an $\mathrm{InP}$ wafer after annealing at $900^{\circ} \mathrm{C}$ for $30 \mathrm{~min}$. with $3 \mathrm{~atm}$ of phosphorus overpressure [48].

the $\mathrm{Ti}$ and $\mathrm{Zn}$ profiles.

The last possibility which should be mentioned is MOVPE growth of SI InP layers co-doped with $\mathrm{Fe}$ and $\mathrm{Ti}$ [50-51]. The material obtained, with resistivities higher than $10^{7} \Omega \mathrm{cm}$, remains SI in the presence of an excess of shallow donors, as well as an excess of shallow acceptors. This material was already used in AT\&T Bell Laboratories for development of low-threshold low-leakage buried lasers, without the use of additional dielectric layers [50].

\section{TM-doped SI GaP crystals}

SI GaP material may be useful for high-temperature electronic applications. SI crystals doped with $\mathrm{Fe}$ [52], and V [53], and also SI layers doped with Cr [54] were reported in the literature. For $\mathrm{Fe}$ - and $\mathrm{Cr}$-doped materials, one may, in spite of their high resistivities (related to the deep positions of these acceptors in the GaP energy gap (see Figs.3 and 8)), expect thermal stability problems like similar to those found for GaAs and InP. In the case of V-doped GaP, the resistivity reported is $3 \times 10^{8} \Omega \mathrm{cm}$ (the vanadium $\mathrm{V}^{3+/ 2+}$ acceptor level is located $0.58 \mathrm{eV}$ below the bottom of the conduction band [53]). This material is expected to be thermally stable. A good method of obtaining even higher resistivity $\mathrm{GaP}$ seems to be co-dopping with $\mathrm{Ti}$ and shallow acceptors. The titanium $\mathrm{Ti}^{4+/ 3+}$ donor level lies about $1 \mathrm{eV}$ above the valence band (see Fig. 10). Another possibility may be co-dopping with $\mathrm{Ti}$ and $\mathrm{Fe}$. 
TABLE I.

Reported SI Ti-doped InP crystals.

\begin{tabular}{c|c|l|l|l|l}
\hline \hline $\begin{array}{c}\text { Growth } \\
\text { techn. }\end{array}$ & Acceptor & $\begin{array}{l}\rho_{300} \\
(\Omega \mathrm{cm})\end{array}$ & $\begin{array}{l}n_{300} \\
\left(\mathrm{~cm}^{-3}\right)\end{array}$ & $\begin{array}{l}\mu_{300} \\
\left(\mathrm{~cm}^{2} / \mathrm{Vs}\right)\end{array}$ & Reference \\
\hline GF & $\mathrm{Hg}$ & $4.7 \times 10^{4}$ & $7.7 \times 10^{10}$ & 1700 & {$[42]$} \\
$\mathrm{GF}$ & $\mathrm{Hg}$ & $5.2 \times 10^{4}$ & $9 \times 10^{10}$ & 1350 & {$[42]$} \\
$\mathrm{GF}$ & $\mathrm{Hg}$ & $7.5 \times 10^{4}$ & $6.3 \times 10^{10}$ & 1300 & {$[42]$} \\
$\mathrm{GF}$ & $\mathrm{Hg}$ & $>5 \times 10^{5}$ & $\cdot$ & & {$[37]$} \\
\hline LEC & $\mathrm{Be}$ & $1 \times 10^{6}$ & $2.5 \times 10^{9}$ & 2500 & {$[46]$} \\
LEC & $\mathrm{Cd}$ & $1.1 \times 10^{6}$ & $2.2 \times 10^{9}$ & 2600 & {$[46]$} \\
LEC & $\mathrm{Zn}$ & $3.3 \times 10^{6}$ & $7.3 \times 10^{8}$ & 2600 & {$[46]$} \\
LEC & $\mathrm{Zn}$ & $1.6 \times 10^{5}$ & $1.5 \times 10^{10}$ & 2600 & {$[47]$} \\
LEC & $\mathrm{Zn}$ & $5 \times 10^{6}$ & $6 \times 10^{8}$ & 2100 & {$[47]$} \\
LEC & $\mathrm{Zn}$ & $1.6 \times 10^{6}$ & $2.1 \times 10^{9}$ & 1830 & {$[48]$} \\
LEC & $\mathrm{Zn}$ & $5.7 \times 10^{6}$ & $7.8 \times 10^{8}$ & 1400 & {$[48]$} \\
\hline LPE & $\mathrm{Zn}$ & $2.3 \times 10^{3}$ & & & {$[49]$} \\
LPE & $\mathrm{Zn}$ & $2.7 \times 10^{4}$ & & & {$[49]$}
\end{tabular}

\section{TM-doped ternary and quaternary compounds}

It should also be noted that the variety of the TM at our disposal gives us a possibility of looking for midgap levels in ternary and quaternary III-V layers. Several examples of such doping may be found in the literature. The most important of these compounds is $\operatorname{In}_{0.53} \mathrm{Ga}_{0.47} \mathrm{As} / \mathrm{InP}$. Its doping with Fe [55], or Ti [56], or both of these [51], were recently reported. Both impurities form mid-gap levels in this compound. The titanium position (at $E_{c}=0.37 \pm 0.02 \mathrm{eV}$ ) is nearly ideal, because $E_{g} / 2=0.75 / 2 \mathrm{eV}=0.375 \mathrm{eV}$. The resistivities obtained are of the order of $10^{3} \Omega \mathrm{cm}$, close to the intrinsic limit.

\section{Conclusions}

In conclusion, one can predict further investigations of new SI materials such as layers of ternary and quaternary compounds doped with $3 d^{n}$ TM impurities, as well as bulk III-V crystals doped with $4 d^{n}$ and $5 d^{n}$ TM impurities. We may also expect further improvements of the SI systems already known. There is no "ideal" SI material, and it is still wanted... 


\section{References}

[1] B. Clerjaud, J. Phys. C (Solid State) 18, 3615 (1985).

[2] B. Clerjaud, in Current Issues in Semiconductor Physics, ed. A.M. Stoneham, Adam Hilger, Bristol 1986, p.117.

[3] A. Zunger, in Solid State Physics, eds. H. Ehrenreich, F. Seitz, D. Turnbull, Academic Press, New York 1986, Vol. 39, p. 275.

[4] A.M. Hennel, in Defects in III-V Compounds, ed. E. Weber, in series Semiconductors and Semimetals, eds. R.K. Willardson, A.C. Beer, Academic Press, New York 1991.(in press).

[5] G.J. Rees (ed.), Semi-Insulating III-V Materials Nottingham 1980, Shiva, Orpington England, 1980.

[6] S. Makram-Ebeid, B. Tuck (eds.), Semi-Insulating III-V Materials Evian 1982, Shiva, Nantwich England, 1982.

[7] D.C. Look, J.S. Blakemore (eds.), Semi-Insulating III-V Materials Kah-nee-ta 1984, Shiva, Nantwich England, 1984.

[8] H. Kukimoto, S. Miyazawa (eds.) Semi-Insulating III-V Materials Hakone 1986, North Holland/OHMSHA, Tokyo 1986.

[9] G. Grossmann, L.A. Ledebo (eds.) Semi-Insulating III-V Materials Malmö 1988, Adam Hilger, Bristol and Philadelphia 1988.

[10] D.C. Look, in Semiconductors, Semimetals, eds. R.K. Willardson, A.C. Beer, Academic Press, New York 1983, Vol.19, p. 75.

[11] E.J. Johnson, J.A. Kafalas, R.W. Davies, J. Appl. Phys. 54, 204 (1983).

[12] J.S. Blakemore, J. Appl. Phys. 53, R123 (1982).

[13] W. Walukiewicz, L. Pawlowicz, J. Lagowski, H.C. Gatos, in Semi-Insulating III-V Materials Evian 1982, eds. S. Makram-Ebeid, B. Tuck, Shiva, Nantwich England, 1982, p. 121.

[14] R.W. Haisty, G.R. Cronin, in Physics of Semiconductors, Dunod, Paris 1964, p. 1161.

[15] I. Grand, D. Rumsby, R.M. Ware, M.R. Brozel, B. Tuck, in Semi-Insulating III-V Materials Evian 1982, eds. S. Makram-Ebeid, B. Tuck, Shiva, Nantwich England, 1982, p. 98.

[16] S. Makram-Ebeid, P. Langlade, G.M. Martin, in Semi-Insulating III-V Materials Kah-nee-ta 1984, eds. D.C. Look, J.S. Blakemore, Shiva, Nantwich England, 1984, p. 184.

[17] B. Tuck, in Semi-Insulating III-V Materials Kah-nee-ta 1984, eds. D.C. Look, J.S. Blakemore, Shiva, Nantwich England, 1984, p. 2.

[18] A.M. White, in Semi-Insulating III-V Materials Nottingham 1980, ed. G.J. Rees, Shiva, Orpington England, 1980, p. 3.

[19] N.T. Linh, A.M. Huber, P. Etienne, G. Morrillot, P. Duchemin, M. Bonnet, in Semi-Insulating III-V Materials Nottingham 1980, ed. G.J. Rees, Shiva, Orpington England, 1980, p. 206.

[20] R.K. Willardson, W.P. Allred, J.E. Cook, U.S.Patent \#3496118 (1970).

[21] B. Clerjaud, B. Devaud, P. Noel, French Patent Appl. \#8513982 (1985).

[22] M. Morioka, A. Shimizu, European Patent Appl. \#85301743.2 (1985). 
[23] K. Fujita, T. Shimoda, S. Yoshitake, T. Inoue, T. Matsutomo, S. Nishine, Y. Sato, M. Shibata, Sumitomo Electric Technical Rev. 26, 185 (1987).

[24] S. Akai, in Compound Semiconductors: Growth, Processing, and Devices, eds. P.H. Holloway, T.J. Anderson, CRC Press, Boca Raton, Florida 1989, p. 3.

[25] W. Kütt, D. Bimberg, M. Maier, H. Krautle, F. Kohl, E. Bauser, Appl. Phys. Lett. 44, 1078 (1984).

[26] H. Terao, H. Sunakawa, K. Ohata, H. Watanabeed, in Semi-Insulating III-V Materials Evian 1982, eds. S. Malkram-Ebeid, B. Tuck, Shiva, Nantwich England, 1982, p. 54.

[27] M. Akiyama, Y. Karawada, K. Kaminishi, J. Crystal Growth 68, 39 (1984).

[28] A.M. Hennel, C.D. Brandt, L.M. Pawlowicz, K.Y. Ko, in Semi-Insulating III-V Materials Hakone 1986, eds. H. Kukimoto, S. Miyazawa, North Holland/OHMSHA, Tokyo 1986, p. 465.

[29] A.M. Hennel, C.D. Brandt, K.Y. Ko, J. Lagowski, H.C. Gatos, J. Appl. Phys. 62, 163 (1987).

[30] K.Y. Ko, J. Lagowski, H.C. Gatos, J. Appl. Phys. 66, 3309 (1989).

[31] W.S. Hobson, S.J. Pearton, V. Swaminathan, A.S. Jordan, H. Kanber, Y.J. Kao, N.M. Haegel, Appl. Phys. Lett. 54, 1772 (1989).

[32] B.W. Straughan, D.T.J. Hurle, K. Loyd, J.B. Mullin, J. Cryst. Growth 3, 281 (1974).

[33] O.Mizuno, H.Watanabe, Electron. Lett. 11, 118 (1975).

[34] E.M. Monberg, H. Brown, S.N.G. Chu, J.M. Parsey, in Semi-Insulating III-V Materials Malmö 1988, eds. G. Grossmann, L.A. Ledebo, Adam Hilger, Bristol and Philadelphia 1988, p. 459.

[35] K. Tada, M. Tatsumi, M. Nakagawa, T. Kawase, S. Akai, in Proc. 14 th Internat. Symposium on GaAs and Related Compounds, Inst. Phys. Conf. Ser. No.91, London 1987, p. 439.

[36] H. Kamada, S Shinoyama, A. Katsui, J. Appl. Phys. 55, 2881 (1984).

[37] Y. Toudic, R. Coquillé, M. Gauneau, G. Grandpierre, B. Lambert, in Advanced Materials for Telecommunications, eds. P.A. Glasow, Y.I. Nissim, J.P. Noblanc, J. Speight, Editions de Physique, Paris 1986, p. 41.

[38] K.L. Hess, S.W. Zehr, W.H. Cheng, J. Pooladdej, K.D. Buehring, D.L. Wolf, J. Cryst. Growth 93, 576 (1988).

[39] B. Clerjaud, in Semi-Insulating III-V Materials Malmö 1988, eds. G. Grossmann, L.A. Ledebo, Adam Hilger, Bristol and Philadelphia 1988, p. 303.

[40] A. Shimizu, S. Nishine, M. Morioka, K. Fujita, S. Akai, in Semi-Insulating III-V Materials Hakone 1986, eds. H. Kukimoto, S. Miyazawa, North Holland/OHMSHA, Tokyo 1986, p. 41.

[41] C.D. Brandt, A.M. Hennel, L.M. Pawlowicz, Y.T. Wu, T. Bryskiewicz, J. Lagowski, H.C. Gatos, Appl. Phys. Lett. 48, 1162 (1986).

[42] B. Lambert, Y. Toudic, R. Coquillé, M. Gauneau, G. Grandpierre, B. Deveaud, in Semi-Insulating III-V Materials Hakone 1986, eds. H. Kukimoto, S. Miyazawa, North Holland/OHMSHA, Tokyo 1986, p. 487. 
[43] Y. Toudic, B. Lambert, R. Coquillé, G. Grandpierre, M. Gauneau, Semicond. Sci. Technol. 3, 464 (1988).

[44] C.D. Brandt, A.M. Hennel, T. Bryskiewicz, K.Y. Ko, L.M. Pawlowicz, H.C. Gatos, J. Appl. Phys. 65, 3459 (1989).

[45] D. Wasik, M. Baj, A.M. Hennel, in Proc. 19th Internat. Conf. Phys. Semicond. Warsaw 1988, ed. W.Zawadzki, Inst. of Physics, Polish Academy of Sciences, Warsaw 1989, p. 1095.

[46] G.W. Iseler, B.S. Ahern, Appl. Phys. Lett. 48, 1656 (1986).

[47] G.W. Iseler, B.S. Ahern, J. Electron. Mater. 15, 299 (1986).

[48] A. Katsui, J. Cryst. Growth 89, 612 (1988).

[49] D.G. Knight, C.J. Miner, W. Benyon, in Semi-Insulating III-V Materials Malmö 1988, eds. G. Grossmann, L.A. Ledebo, Adam Hilger, Bristol and Philadelphia 1988, p. 259.

[50] A.G. Dentai, C.H. Joyner, T.W. Weidman, in Proc. 14th Internat. Symposium on GaAs and Related Compounds, Inst. Phys. Conf. Ser. No.91, London 1987, p. 283.

[51] T. Wolf, A. Krost, D. Bimberg, F. Reier, H. Schumann, in Semi-Insulating III-V Materials Toronto 1990, in press.

[52] D.G. Andrianow, P.M. Grinshtein, G.K. Ippolitova, E.M. Omel'yanowskii, N.I. Suchkova, V.I. Fistul', Sov. Phys. Semicond. 10, 696 (1976).

[53] W. Ulrici, L. Eaves, K. Friedland, D.P. Halliday, Phys. Status Solidi $B$ 141, 191 (1987).

[54] I.J. Fritz, R.M. Biefeld, R.C. Hughes, Appl. Phys. Lett. 41, 974 (1982).

[55] Z. Chen, T. Wolf, W. Korb, D. Bimberg, J. Appl. Phys. 64, 4574 (1988).

[56] Z. Chen, W. Korb, R.K. Bauer, D. Bimberg, Appl. Phys. Lett. 55, 645 (1989). 